\title{
NRIP/DCAF6 stabilizes the androgen receptor protein by displacing DDB2 from the CUL4A-DDB1 E3 ligase complex in prostate cancer
}

\author{
Hsin-Hsiung Chen ${ }^{1, *}$, Ping Fan ${ }^{1, *}$, Szu-Wei Chang ${ }^{1, *}$, Yeou-Ping Tsao ${ }^{2}$, Hsiang-Po \\ Huang $^{3}$, Show-Li Chen ${ }^{1}$ \\ ${ }^{1}$ Graduate Institute of Microbiology, College of Medicine, National Taiwan University, Taipei 100, Taiwan \\ ${ }^{2}$ Department of Ophthalmology, Mackay Memorial Hospital, Taipei 104, Taiwan \\ ${ }^{3}$ Graduate Institute of Medical Genetics and Proteomics, College of Medicine, National Taiwan University, Taipei 100, Taiwan \\ *These authors have contributed equally to this work \\ Correspondence to: Show-Li Chen, email: showlic@ntu.edu.tw \\ Hsiang-Po Huang, email: hh691290@gmail.com
}

Keywords: NRIP/DCAF6, DDB2, AR, CUI4-DDB1, cribriform prostate cancer

Received: October 27, 2016

Accepted: January 27, 2017

Published: February 14, 2017

\section{ABSTRACT}

Both nuclear receptor interaction protein (NRIP) and DNA damage binding protein 2 (DDB2) belong to the Cullin 4 (CUL4)-DDB1 binding protein family and are androgen receptor (AR)-interacting proteins. Here, we investigated the expression patterns of the NRIP, DDB2 and AR proteins in human prostate cancer tissues and found that the expression levels of NRIP and AR were higher, but the DDB2 level was lower, in prostate cancer tissues than in non-neoplastic controls, suggesting NRIP as a candidate tumor promoter and DDB2 as a tumor suppressor in prostate cancer. Furthermore, both NRIP and DDB2 shared the same AR binding domain; they were competitors for the AR, but not for DDB1 binding, in the AR-DDB2-DDB1-CUL4A complex. Conclusively, NRIP stabilizes the AR protein by displacing DDB2 from the AR-DDB2 complex. Consistent with our hypothesis, a specific expression pattern with high levels of NRIP and AR, together with a low level of DDB2, was found more frequently in the human prostate cancer tissues with a cribriform pattern than in non-cribriform tumors, suggesting that disruption of the balance between NRIP and DDB2 may change AR protein homeostasis and contribute to pathogenesis in certain aggressive types of prostate cancer.

\section{INTRODUCTION}

Previously, we determined that the nuclear receptor interaction protein (NRIP; also named DCAF6 and IQWD1) is a transcriptional cofactor that enhances androgen receptor (AR)-mediated transcriptional activity [1] and an AR-targeted gene. In addition, NRIP can protect the AR protein from proteasome degradation, although the mechanism is unclear [2]. NRIP also has been reported to be a member of the DDB1 and Cullin 4 (CUL4)-associated factors (DCAF) family [3]. The NRIP protein is composed of 860 amino acids and contains seven WD-40 repeats and one IQWD1 [1]. Moreover, we also found that NRIP is a human papillomavirus 16 E2-interacting protein and acts as a scaffold to recruit E2 and calcium/calmodulin to prevent polyubiquitination and degradation of E2, resulting in enhanced E2 stability [4]. NRIP is associated with human diseases, high expression levels of IQWD1 (NRIP) in breast cancer tissues are significantly associated with adverse clinical outcomes [5] and NRIP expression is found in six human malignancies (esophageal, colon, breast, ovarian, skin and pancreatic cancers) [6]. NRIP is also one of the candidate genes involved in cerebral visual impairment, which is causally related to variants of one or multiple genes, including NRIP, with an autosomal recessive transmission pattern [7].

DNA damage binding protein 2 (DDB2, also named p48 and XPE), like NRIP, belongs to the DCAF family [8]. Recent reports indicate that the DDB2-DDB1-CUL4 complex is involved in the nucleotide excision DNA repair (NER) pathway response to UV irradiation [9] and protein degradation control $[10,11]$. NormalDDB2 is an important 
component of the NER pathway that, when impaired, may cause xeroderma pigmentosum [12], human skin cancer $[13,14]$, and tobacco-related lung cancer [15]. In addition, DDB2 inhibits tumor growth by various mechanisms, such as limiting the cancer stem cells in ovarian cancer [16, 17]. The DDB2 protein level is reduced in high-grade colon cancers [18]. DDB2 can suppress the invasion of breast cancer by decreasing NF- $\mathrm{BB}$ activity $[19,20]$ and indirectly suppresses ovarian cancer proliferation [21]. Hence, DDB2 also acts as a tumor suppressor. In terms of DDB2 functions in ubiquitination and degradation, a current report revealed that DDB2 could facilitate tumorigenesis of gastric cancer via ubiquitination and degradation of the tumor suppressor progestin and adipoQ receptor family member 3 [22]. Similarly, we also found that DDB2 mediates ubiquitination and degradation of the AR via the CUL4A-DDB1 E3 ligase complex [23].

The AR is causally linked to prostate cancer and androgen-AR signaling is critical for prostate cancer development and progression [24, 25]. In general, androgen binds to the AR; the bound AR molecules become homodimers and translocate into the nucleus, binding to the cognate DNA response elements. Coregulators (coactivators and corepressors) are then recruited to increase or decrease the signals of the hormones to the transcriptional machinery and result in the initiation and progression of prostate cancer [26]. Therefore, most prostate cancers can be treated initially by androgen deprivation. However, due to increased protein levels of AR or AR mutations that cause AR-resistance to anti-androgen treatment, patients may relapse, with the development of a castration-therapy-resistant stage of prostate cancer [27]. Consequently, it would be interesting to investigate the correlation between AR-interacting proteins and prostate cancer. Previously, we found that both NRIP and DDB2 are AR-interacting proteins [23], and belong to the DCAF-associated protein family. Therefore, we were interested in examining the NRIP, DDB2 and AR protein expression profiles in human prostate tumors with the aim of elucidating the interaction mechanism of these three proteins and their roles in prostate cancer. Here, we showed that NRIP, like DDB2, was a DCAF-associated protein and could form a CUL4A-DDB1 complex. NRIP and DDB2 bound to the same domain of the AR protein. Hence, NRIP attenuated the association between DDB2 and the AR and an NRIP mutant that lacks DDB1 binding ability was still capable of interfering with the interaction between DDB2 and AR, indicating that NRIP and DDB2 are competitors for the AR, but not for DDB1 binding, in the AR-DDB2-DDB1-CUL4A complex. In clinical significance, NRIP was a candidate tumor promoter and DDB2 was a tumor suppressor in prostate cancer. The relationship between the expression of NRIP, AR and DDB2 and the pathological sub-types of prostate cancer, we found that a specific pattern of high expression of NRIP and AR and simultaneous low expression of DDB2 was detected more frequently in cribriform tumors than in non-cribriform tumors.

\section{RESULTS}

\section{NRIP is highly expressed in prostate tumors}

Our previous study showed that NRIP stabilizes the AR protein and up-regulates the expression of prostatespecific antigen (PSA) [2]. Because the AR is crucial in prostate cancer progression, according to many studies $[24,28]$, and the PSA test is widely used for prostate cancer screening for men after the age of 50 (National Cancer Institute Website: www.cancer.gov). We were interested in evaluating the expression of NRIP in prostate cancer tissues; the immunohistochemistry results indicated that the NRIP protein was expressed in the nuclei and cytoplasm of luminal and basal cells (Figure 1A, nonneoplastic tissue). A high level of NRIP expression was defined as a score greater than or equal to 150 and a score less than 150 was defined as low expression. The result (Figure 1B) was that the percentage of cases which scored as high expression for NRIP was greater for neoplastic tissues than for non-neoplastic tissues (non-neoplastic vs. neoplastic $=57.1 \%$ vs. $81.0 \% ; P<0.005)$. We further divided these prostate tumors into three sub-categories (Figure 1B) according to their Gleason Scores (GS) (less than or equal to 6 , equal to 7 , and greater than or equal to 8). Similarly, each sub-category had a significantly greater $(P<0.05)$ percentage of high-NRIP neoplastic tissues than the non-neoplastic group (Figure 1B); indicating that high score GS patients have more NRIP expression than non-neoplastic prostate. Moreover, when the average expression scores of different sub-categories were compared, NRIP expression in the GS $\geq 8$ subcategory was significantly higher than the $\leq 6$ subcategory $(\mathrm{P}=$ $0.025)$ and the non-neoplastic prostate $(\mathrm{P}=0.023)$ (Figure 1C). But there were no significant differences between any other pairs of these four sub-categories in terms of the percentage of high NRIP expression (Figure 1C). Collectively, NRIP expression is up-regulated in human prostate cancer and may be positively correlated with tumorigenesis; cancers with higher Gleason scores have higher levels of NRIP expression than cancer tissues with lower Gleason Scores.

\section{Expression of the AR protein in human prostate cancer}

According to many studies, the AR is important in prostate cancer progression $[24,25,28]$. However, whether AR expression is related to the prostate cancer stage and outcome remains controversial, because inconsistent results have been reported [29]. Therefore, we sought to evaluate the AR expression levels in our prostate tissues and to correlate these with tumor grading and NRIP 
expression. Expression of the AR was predominantly in the nucleus of non-neoplastic and neoplastic tissues (Figure 2A). Similar to NRIP, the percentage of highAR cases was significantly greater $(P<0.005$ for each comparison in Figure $2 \mathrm{~B}$ ) in human prostate cancer (either all tumors or any sub-category with $\mathrm{GS} \leq 6,7$, or $\geq 8$ ) than in non-neoplastic prostate tissues (Figure 2B). An analysis comparing the average expression scores among different sub-categories also yielded similar results (Figure 2C). Collectively, AR expression is significantly higher in our prostate cancer tissues than non-neoplastic tissues. Previously, we reported that NRIP could increase and stabilize AR protein in LNCaP cells [2]. Thereof, we further compared the expression levels of NRIP and AR in prostate cancer tissues analyzed by immunohistochemistry. Table 1 showed a significantly positive correlation (the odds ratio $=2.10,95 \%$ confidence interval $=1.04-4.26$, $P$ value $=0.0376$ ) between the expression levels of NRIP and AR, supporting the hypothesis in our previous study that NRIP increases the expression of AR protein [2].

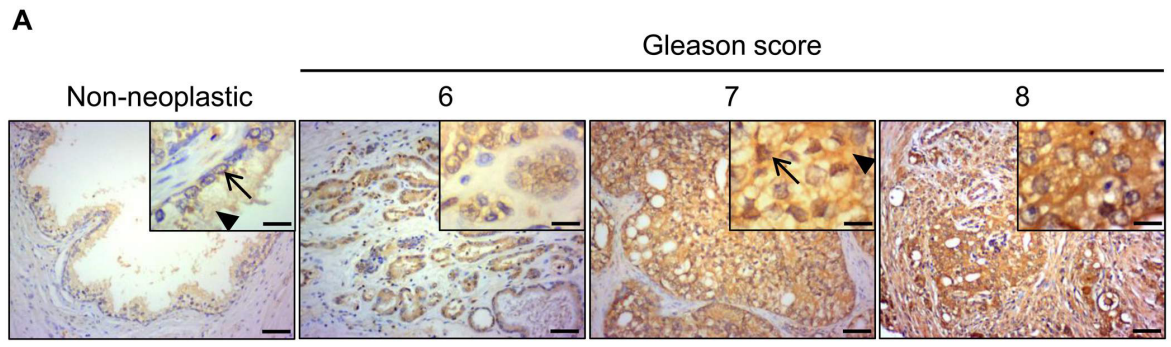

B

\begin{tabular}{|c|c|c|c|c|c|c|}
\hline & \multirow{2}{*}{$\begin{array}{l}\text { Protein } \\
\text { expression }\end{array}$} & \multirow{2}{*}{$\begin{array}{c}\text { Non- } \\
\text { neoplastic } \\
(n=28)\end{array}$} & \multicolumn{4}{|c|}{ Neoplastic Gleason score } \\
\hline & & & $\begin{array}{c}\leq 6 \\
(n=51)\end{array}$ & $\begin{array}{c}7 \\
(n=75)\end{array}$ & $\begin{array}{c}\geq 8 \\
(n=106)\end{array}$ & $\begin{array}{c}\text { Total } \\
(n=232)\end{array}$ \\
\hline \multirow[t]{2}{*}{ NRIP } & High & $16(57.1 \%)$ & $40(78.4 \%)$ & $58(77.3 \%)$ & $90(84.9 \%)$ & $188(81.0 \%)$ \\
\hline & Low & $12(42.9 \%)$ & $11(21.6 \%)$ & $17(22.7 \%)$ & $16(15.1 \%)$ & $44(19.0 \%)$ \\
\hline \multicolumn{3}{|c|}{ Pearson's chi-square } & $\begin{array}{c}\text { Non- } \\
\text { neoplastic } \\
\text { vs. GS } \leq 6\end{array}$ & $\begin{array}{c}\text { Non- } \\
\text { neoplastic } \\
\text { vs. GS } 7\end{array}$ & $\begin{array}{c}\text { Non- } \\
\text { neoplastic } \\
\text { vs. GS } \geq 8\end{array}$ & $\begin{array}{c}\text { Non- } \\
\text { neoplastic } \\
\text { vs. neoplastic }\end{array}$ \\
\hline \multicolumn{3}{|c|}{$p$ value } & 0.0463 & 0.0427 & 0.0013 & 0.0036 \\
\hline
\end{tabular}

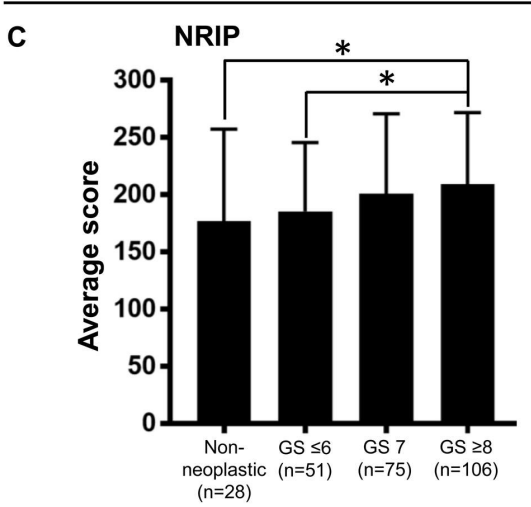

Figure 1: NRIP expression is increased in human prostate cancer tissues compared to non-neoplastic prostate tissues. A. Representative images of immunohistochemistry staining for NRIP expression in non-neoplastic prostate tissues $(\mathrm{n}=28)$ and prostate cancer tissues $(n=232)$, including Gleason Score $\leq 6(n=51)$, Gleason Score $=7(n=75)$, and Gleason Score $\geq 8(n=106)$. Left to right represent non-neoplastic, Gleason Score $\leq 6$, Gleason Score $=7$, and Gleason Score $\geq 8$ groups. Brown: NRIP. Blue: hematoxylin counterstain. Upper right insets: magnified figures, Scale bar $=12.5 \mu \mathrm{m}$ for insets, $50 \mu \mathrm{m}$ for others. Arrow: NRIP expression in nucleus; arrowhead: cytosol expression. B. Comparison of the NRIP expression levels in non-neoplastic tissues and tumors of different grades. The intensity of NRIP expression was scored as follows: $0=$ negative staining, $1=$ weak brown staining, $2=$ intermediate brown staining, and $3=$ dark brown staining. The extent was scored as the percentage (scored as $0-100 \%$ ) of the positively-stained area. The total score was the product of the intensity and extent scores, from 0 to 300. The score equal to or greater than 150 was defined as "high" expression and otherwise as "low" expression. Statistical analysis was performed using Pearson's chi-square test. GS, Gleason Score. C. The NRIP expression level, based on its average immunohistochemistry score, was significantly higher $(P=0.025$, Student's t test $)$ in tumors with Gleason Score $\geq 8(n=106)$ than in tumors with Gleason Score $\leq 6(n=51)$. Other comparisons, i.e. GS $\geq 8$ vs. GS $=7$, or GS $=7$ vs. GS $\leq$ 6 , did not show significant difference. ${ }^{*}, P<0.05$. 
Table 1: The numbers of prostate cancer tissues with either high or low expression levels of AR and NRIP in immuno histochemistry

\begin{tabular}{|c|c|c|c|c|c|}
\hline & & \multicolumn{3}{|c|}{ NRIP } & \multirow{2}{*}{ P value } \\
\hline & & High & Low & Total & \\
\hline \multirow[t]{3}{*}{$\mathbf{A R}$} & High & 88 & 13 & 101 & \\
\hline & Low & 100 & 31 & 131 & \\
\hline & Total & 188 & 44 & 232 & $<0.05$ \\
\hline
\end{tabular}

The staining scores (described in Methods) higher than 150 were defined as having "high" expression and otherwise as "low" expression. Odds ratio: 2.10; 95\% confidence interval: 1.04 - 4.26; Chi square $\mathrm{P}$ value $=0.0376$.

\section{Expression of the DDB2 protein in human prostate cancer}

Previously, we found that DDB2 interacts with the AR [23]. In addition, DDB2 reportedly acts as a tumor suppressor in a wide range of cancers [16-21, 30,31]. The relationship between DDB2 and prostate cancer remains unclear. We then investigated DDB2 protein expression in human prostate cancer tissues and found that the DDB2 protein was expressed predominately in the nuclei of basal cells and rarely in luminal cells in normal prostate tissues (Figure 3A), a result consistent with previous reports that DDB2 is a nuclear protein, and the nuclear signal of DDB2 expression is exclusively used for immunohistochemistry evaluation in human colon cancer tissues [18, 32]. Using a similar scoring system, we compared DDB2 expression in non-neoplastic and neoplastic tissues and found, in contrast to NRIP and AR, a greater percentage $(P<0.05$ for each comparison in Figure 3B) of high-DDB2 cases in the non-neoplastic tissues than prostate cancers (either all tumors or any sub-category with GS $\leq 6,7$, or $\geq 8$ ) (Figure $3 \mathrm{~B})$. In addition, an analysis comparing the average expression scores among different sub-categories also yielded similar results (Figure 3C). Collectively, DDB2 expression is down-regulated in human prostate cancer.

Because DDB2 reportedly promotes the ubiquitination and degradation of $\mathrm{AR}$ in $\mathrm{LNCaP}$ cell lines [23], we next examined the relationship between DDB2 and AR protein expression in human prostate cancer tissues. However, the result showed a positive correlation (odds ratio: 3.24, confidence interval: 1.775.96) between the AR and DDB2 in human prostate cancer tissues (Supplementary Table 1A); it contradicted in vitro conclusion of DDB2-degrading AR. Furthermore, by separating the original Supplementary Table 1A into two groups: one with low expression of NRIP (Supplementary Table 1B) and the other with high expression of NRIP (Supplementary Table 1C), we found that a positive correlation between the expression of DDB2 and AR $(P$ $=0.00073$ ) only existed in the group with high expression of NRIP; but not in the low-NRIP group. Since tumors are very heterogeneous; it is probable that in some tumors, high expression of AR may stimulate the expression of
DNA repair-related genes including DDB2 and in these cases tumor cells may have developed other strategies to antagonize DDB2. We reasoned that a high level of NRIP might antagonize the destabilizing effect of DDB2 and protect AR; allowing tumors to express a high level of DDB2 for other purposes, a phenomenon that complies with our hypothesis.

\section{NRIP competes with DDB2 to protect the AR from protein degradation}

NRIP is a DCAF protein and is also known as DCAF6 and IQWD1 [3]. DCAFs are a family of proteins that associate with DDB1 and CUL4 and serve as receptors for substrates that recruit E3 ligase to the DDB1-CUL4 complex [33]. Because NRIP expression is correlated with AR expression in human prostate tumors (Table 1); we were interested in understanding the mechanism for positive correlation between NRIP and AR. Therefore, we examined the interactions of NRIP with proteins pulled down from nuclear extracts of HeLa cells. Based on molecular weight of CUL4A (87 kD) and DDB1 $(127 \mathrm{kD})$, we localized the positions of these two proteins in gel (Figure 4A, upper panel); and western blot assay confirmed each relative location of CUL4A and DDB1 (lower). Interestingly, the western blot results suggested that much more CUL4A molecules (strong band) than DDB1 bound to NRIP; one reason could be the CUL4ADDB1 complex containing more CUL4A molecules than DDB1, the other might be stronger anti-CUL4A antibody than anti-DDB1 antibody. Hence, Figure 4A indicated that NRIP might bind to the DDB1-CUL4A complex. To determine whether NRIP binds to DDB1 in cells, the interaction between NRIP and DDB1 was examined in 293 T cell and observed reciprocally (Figure 4B, lane 4). Recent reports have shown that DCAF proteins contain WD40 repeats and the interaction between DCAFs and DDB1 is through a WDXR motif in the WD40 repeat $[3,34]$. The WDXR motif in WD40 repeats is followed occasionally by an X-Arg dipeptide or X-Lys dipeptide. As shown in Figure 4C, NRIP contains two predicted WDXR motifs in its third and fourth WD40 repeat, based on the amino acid analysis. To further map the DDB1- 
interaction site of NRIP, we generated a double point mutant (NRIP-DM with arginine [R] at aa 173 and aa 223 changed by site-directed mutagenesis to alanine [A]) in these two WDXR motifs. To confirm that the two WDXR motifs on NRIP bind DDB1, 293T cells were cotransfected with the expression vectors for HA-tagged DDB1 and FLAG-tagged NRIP wild type or NRIP-DM and co-immunoprecipitation was performed, showing that NRIP-DM failed to bind to DDB1 (Figure 4D, lane 2). Hence, these two WDXR motifs of NRIP are necessary for DDB1 binding. Previously we showed that NRIP binds with the AR and stabilizes it [2]. We sought to determine whether loss of DDB1 binding affects AR protein stability and found that NRIP-DM associated with AR reciprocally in cells (Figure 4E, lane 1). NRIP-DM can bind to AR but not to DDB1. We overexpressed NRIP and NRIP-DM in LNCaP cells with or without DHT treatment to observe the protein expression and transcriptional activity of AR by western blotting (WB) and RT-PCR analysis of PSA. The WB showed that both overexpression of NRIP and NRIP-

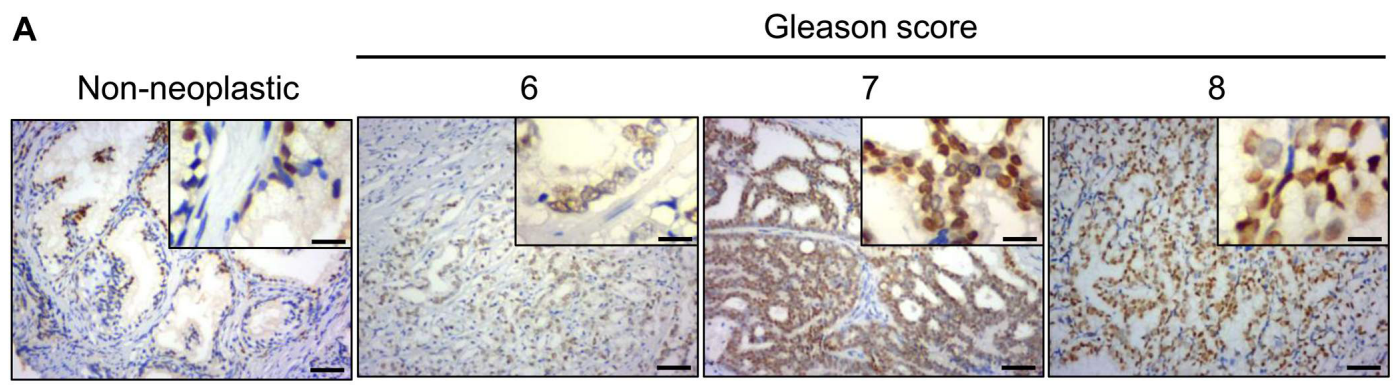

B

\begin{tabular}{|c|c|c|c|c|c|c|}
\hline \multirow{2}{*}{\multicolumn{2}{|c|}{$\begin{array}{l}\text { Protein } \\
\text { expression }\end{array}$}} & \multirow{2}{*}{$\begin{array}{c}\text { Non- } \\
\text { neoplastic } \\
(n=28)\end{array}$} & \multicolumn{4}{|c|}{ Neoplastic Gleason score } \\
\hline & & & $\begin{array}{c}\leq 6 \\
(n=51)\end{array}$ & $\begin{array}{c}7 \\
(n=75)\end{array}$ & $\begin{array}{c}\geq 8 \\
(n=106)\end{array}$ & $\begin{array}{c}\text { Total } \\
(n=232)\end{array}$ \\
\hline \multirow[t]{2}{*}{ AR } & High & $3(10.7 \%)$ & $23(45.1 \%)$ & $31(41.3 \%)$ & $47(44.3 \%)$ & $101(43.5 \%)$ \\
\hline & Low & $25(89.3 \%)$ & $28(54.9 \%)$ & $44(58.7 \%)$ & $59(55.7 \%)$ & $131(56.5 \%)$ \\
\hline \multicolumn{3}{|c|}{ Pearson's chi-square } & $\begin{array}{c}\text { Non- } \\
\text { neoplastic } \\
\text { vs. GS } \leq 6\end{array}$ & $\begin{array}{c}\text { Non- } \\
\text { neoplastic } \\
\text { vs. GS } 7\end{array}$ & $\begin{array}{c}\text { Non- } \\
\text { neoplastic } \\
\text { vs. GS } \geq 8\end{array}$ & $\begin{array}{c}\text { Non- } \\
\text { neoplastic } \\
\text { vs. neoplastic }\end{array}$ \\
\hline \multicolumn{3}{|c|}{$p$ value } & 0.0019 & 0.0033 & 0.0011 & 0.0008 \\
\hline
\end{tabular}

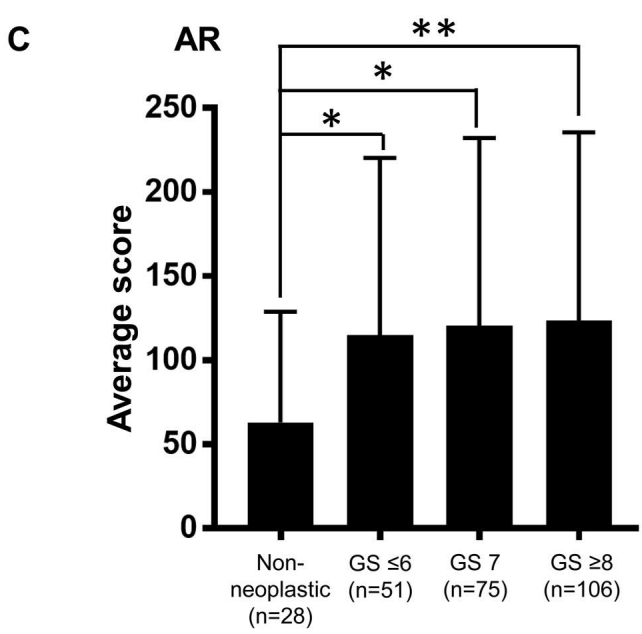

Figure 2: AR expression is increased in human prostate cancer tissues compared to non-neoplastic prostate tissues. A. Representative images of immunohistochemistry staining for AR expression. Left to right represent non-neoplastic, Gleason Score $\leq 6$, Gleason Score $=7$, and Gleason Score $\geq 8$ groups. Brown: AR. Blue: hematoxylin counterstain. Upper right insets: magnified figures, Scale bar $=12.5 \mu \mathrm{m}$ for insets, $50 \mu \mathrm{m}$ for others. B. Comparison of the AR expression levels in non-neoplastic tissues and tumors of different grades. C. Comparison of AR expression level, based on its average immunohistochemistry score. The calculation of the immunohistochemistry score of AR expression and definition of "high" and "low" expression was the same as in Figure 1. *, $P<0.05 ; * *, \mathrm{P}<0.01$. 
DM enhanced the expression of AR protein compared to GFP and mock control with (Figure 4F, lanes 6 and 7). The transcription of PSA, a target gene of AR, was upregulated in both NRIP and NRIP-DM overexpressing LNCaP cells, with DHT treatment (Figure 4F). There was slightly increased AR protein by NRIP-DM mutant in comparison with GFP alone in the absence of DHT
(Figure 4F lane 3 and lane 4); the mild increase of AR was coupled with the mild increase of PSA RNA from three individual experiments. In summary, both NRIP and NRIP-DM (DDB1-binding deficient NRIP) can enhance AR protein stability.

Previously, DDB2 was found to degrade the AR via the CUL4A-DDB1 E3 ligase complex in LNCaP cells

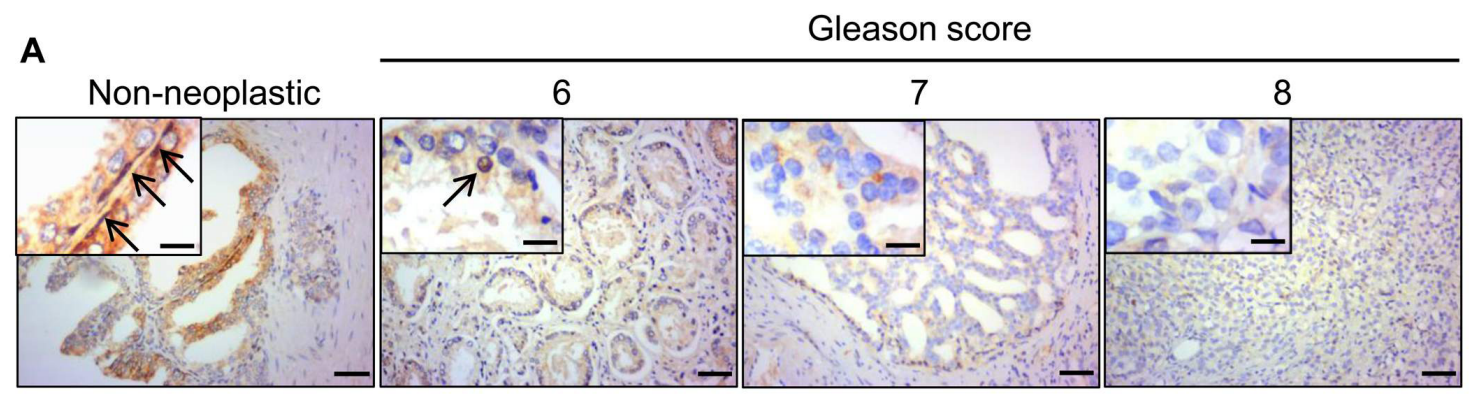

B

\begin{tabular}{|c|c|c|c|c|c|c|}
\hline & \multirow{2}{*}{$\begin{array}{l}\text { Protein } \\
\text { expression }\end{array}$} & \multirow{2}{*}{$\begin{array}{c}\text { Non- } \\
\text { neoplastic } \\
(n=28)\end{array}$} & \multicolumn{4}{|c|}{ Neoplastic Gleason score } \\
\hline & & & $\begin{array}{c}\leq 6 \\
(n=51)\end{array}$ & $\begin{array}{c}7 \\
(n=75)\end{array}$ & $\begin{array}{c}\geq 8 \\
(n=106)\end{array}$ & $\begin{array}{c}\text { Total } \\
(n=232)\end{array}$ \\
\hline \multirow[t]{2}{*}{ DDB2 } & High & $15(53.6 \%)$ & $15(29.4 \%)$ & $14(18.7 \%)$ & $33(31.1 \%)$ & $62(26.7 \%)$ \\
\hline & Low & $13(46.4 \%)$ & $36(70.6 \%)$ & $61(81.3 \%)$ & $73(68.9 \%)$ & $170(73.3 \%)$ \\
\hline \multicolumn{3}{|c|}{ Pearson's chi-square } & $\begin{array}{c}\text { Non- } \\
\text { neoplastic } \\
\text { vs. GS } \leq 6\end{array}$ & $\begin{array}{c}\text { Non- } \\
\text { neoplastic } \\
\text { vs. GS } 7\end{array}$ & $\begin{array}{c}\text { Non- } \\
\text { neoplastic } \\
\text { vs. GS } \geq 8\end{array}$ & $\begin{array}{c}\text { Non- } \\
\text { neoplastic } \\
\text { vs. neoplastic }\end{array}$ \\
\hline \multicolumn{3}{|c|}{$p$ value } & 0.0343 & 0.0005 & 0.0276 & 0.0033 \\
\hline
\end{tabular}

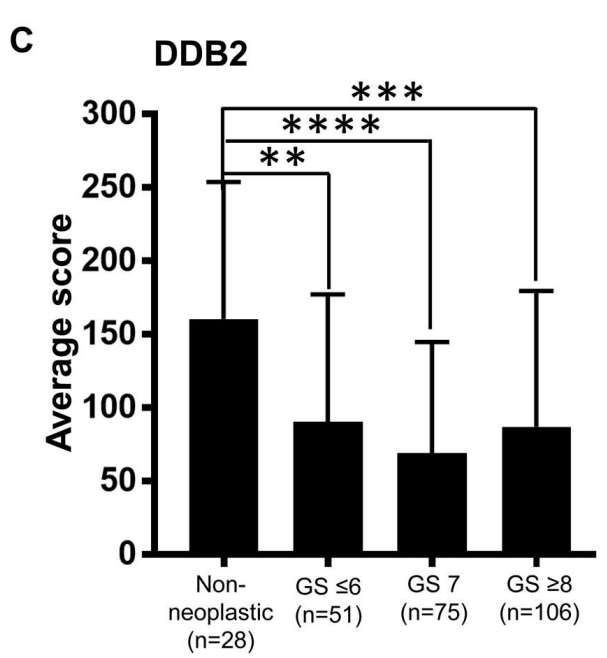

Figure 3: DDB2 expression is decreased in human prostate cancer tissues compared to non-neoplastic prostate tissues. A. Representative images of immunohistochemistry staining for DDB2 expression. Brown: DDB2. Blue: hematoxylin counterstain. Upper right insets: magnified figures, Scale bar $=12.5 \mu \mathrm{m}$ for insets, $50 \mu \mathrm{m}$ for others. Arrow: nuclear DDB2 expression. B. Comparison of the DDB2 expression levels between non-neoplastic tissues and tumors of different grades. The immunohistochemistry score was calculated as described in Figure 1: However, due to the generally lower expression of DDB2 compared to NRIP and AR, the DDB2 staining scores equal to or greater than 125 was defined as "high" expression and otherwise as "low" expression. GS, Gleason score. C. Comparison of DDB2 expression level, based on its average immunohistochemistry score. **, $P<0.01$; ***, $P<0.001 ; * * * *, P<0.0001$. 


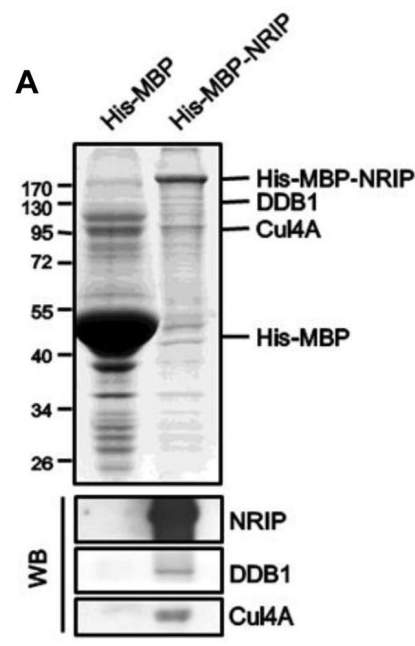

C NRIP:
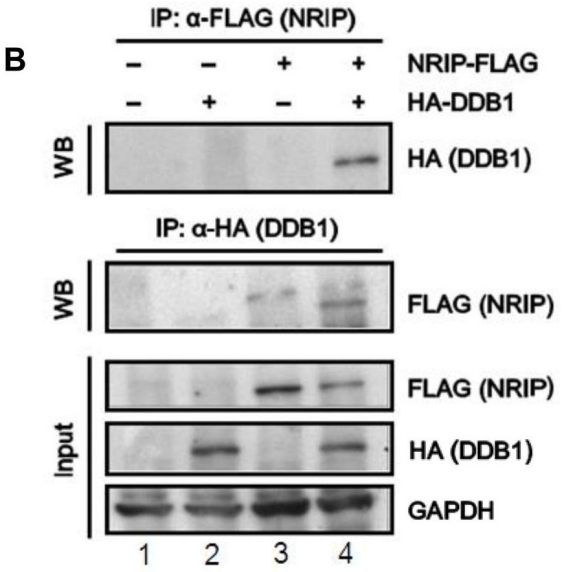

D
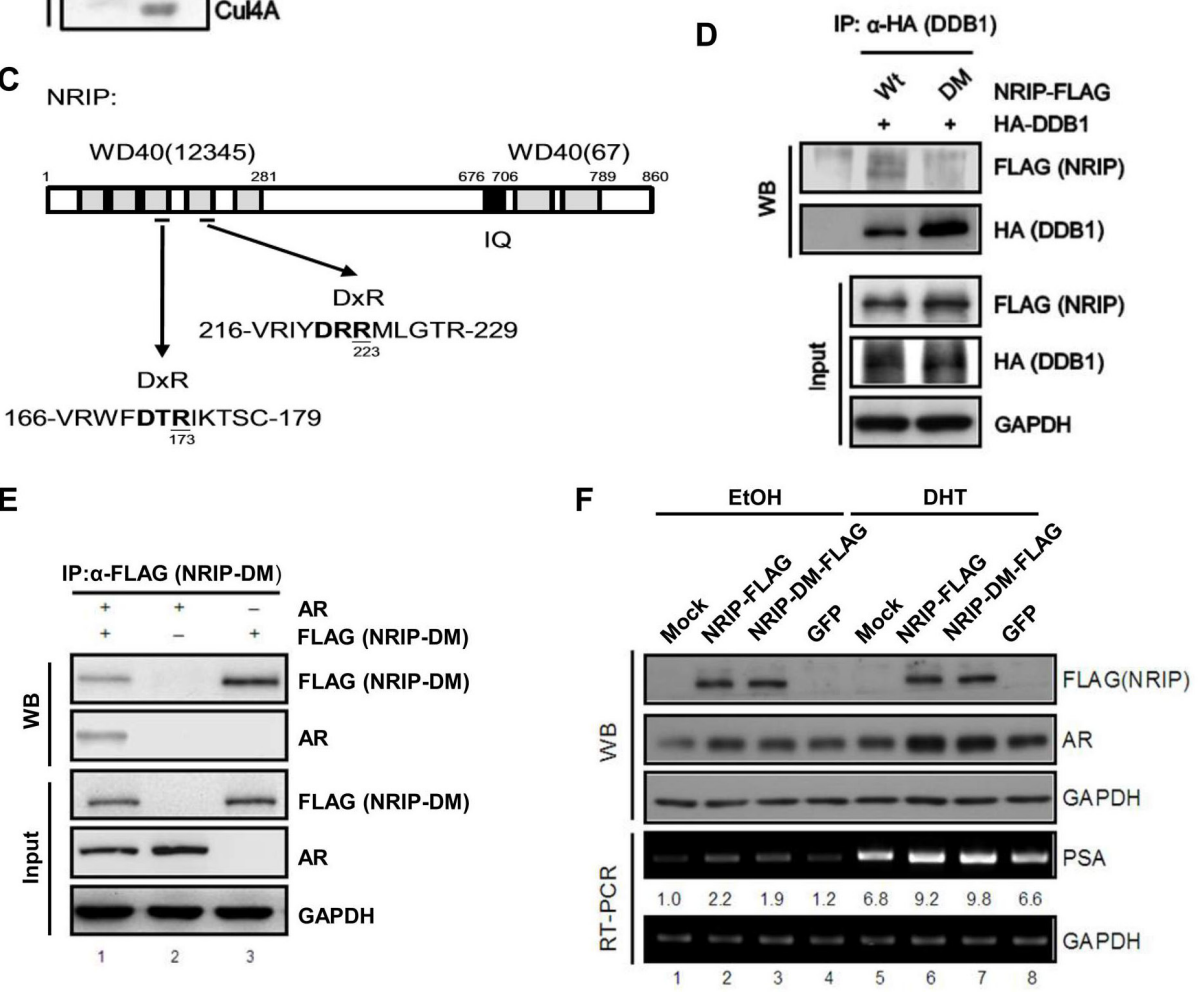

Figure 4: NRIP is involved in the CUL-DDB1 E3 ligase mechanism by interacting with DDB1 and associating with the DDB1-CUL4 complex through its DxR motif. A. NRIP is involved in the CUL4A-DDB1 complex. His-MBP and His-MBP-NRIP were expressed from bacteria and purified using Ni-NTA beads. The beads conjugated with recombinant proteins were incubated with the lysates of HeLa cells and the co-purified proteins were separated by SDS-PAGE and analyzed by Coomassie blue staining (upper panel) or western blotting (lower panel) using the antibodies indicated. B. The interaction between NRIP and DDB1. Calcium phosphate was used to transfect 293T cells with NRIP-FLAG and HA-DDB1 plasmids. Cell lysates were collected $48 \mathrm{~h}$ after transfection and immunoprecipitated with anti-FLAG or anti-HA antibodies for detection of NRIP or DDB1, respectively. C. A schematic depiction of the protein DxR motif of NRIP. Aspartic acids at 173 and 223 in the regions bounded by amino acid residues 166 to 179 and 216 to 229 were replaced by alanine using site-directed mutagenesis and named NRIP-DM. D. NRIP-DM lost DDB1 binding. 293T cells were cotransfected with the wild-type NRIP or NRIP-DM mutant with HA-DDB1, cell lysates were extracted and immunoprecipitated with anti-HA antibodies for detection of DDB1 and immunoblotted with anti-FLAG for detection of NRIP and NRIP-DM. E. NRIP-DM interacted with AR. After cotransfection of 293T cells with FLAG-tagged NRIP-DM and AR, cell extracts were subjected to immunoprecipitation with anti-FLAG or anti-AR antibodies and the immunoprecipitated proteins analyzed by western blotting using anti-AR or anti-FLAG antibodies, reciprocally. The loading of the cell extracts represents $10 \%$ of the input used for immunoprecipitation to assess comparable protein levels. F. AR protein stabilization was independent of NRIP and DDB1 interaction. LNCap cells were transfected with NRIP-FLAG, NRIP-DM-FLAG, and GFP, respectively. After $24 \mathrm{~h}$, cells were treated with $10 \mathrm{nM}$ DHT for $24 \mathrm{~h}$. Proteins and RNAs were extracted by RIPA and Trizol reagent, respectively. The protein expression of NRIP and AR was detected by western blot analysis with anti-FLAG and anti-AR primary antibodies. The expression of PSA was detected by RT-PCR. GAPDH was used as a loading control. 
[23]. Here, we demonstrated that DDB2 expression is reduced in human prostate cancer (Figure 3). On the other hand, NRIP, like DDB2, is a DCAF-associated protein and can form a CUL4A-DDB1 complex (Figure 4A) and NRIP can protect $A R$ protein stability. To determine whether NRIP prevents DDB2-mediated degradation of the AR, we first identified the domain of the AR that binds NRIP. The structure of the AR comprises an N-terminal regulatory domain, including activation function 1 (AF-1), a DNA binding domain (DBD), and a C-terminal hormone-binding domain (HBD) [35]. Reciprocal coimmunoprecipitation indicated that AR- $\triangle$ HBD could not interact with NRIP by NRIP pull-down assay (Figure 5A, lower panel, lane 9); similarly, no NRIP band was observed by AR- $\Delta$ HBD pulldown assay (lane 13). Collectively, NRIP bound to AR through its hormone-binding domain. From NRIP pulldown assay, truncated AR- $\Delta 188$ and AR- $\Delta 488$ mutants consistently had stronger binding affinity to NRIP than AR wild type from three individual experiments, indicating that the structures of these truncated AR proteins might be more feasibly to interact with NRIP. Taken together, NRIP binds to the HBD of the AR.

On the other hand, DDB2 also can bind to the AR [23]. To map which domain of AR DDB2 binds to, we used a GST-pull down assay to investigate DDB2 binding to various AR mutants. As shown in Figure 5B, the binding of DDB2 to the AR was abrogated when the C-terminal HBD was deleted from the AR (Figure 5B, lower panel). The data in Figure $5 \mathrm{~A}$ and $5 \mathrm{~B}$ indicate that NRIP and DDB2 bind to the same domain (HBD) of the AR protein. Therefore, it was interesting to investigate whether NRIP can interfere with the association between DDB2 and the AR; LNCaP cells were cotransfected with plasmids encoding Myc-DDB2 and increasing amounts of NRIP-FLAG. Coimmunoprecipitation with anti-AR antibodies (Figure 5C) showed that less DDB2 protein was associated with the AR protein in the presence of a high dose NRIP (Figure 5C, lane 3 ). In vitro competition by GST-pull down assay also showed that increased NRIP protein could attenuate GST-DDB2 binding to the AR protein (Figure 5D, lanes 3 to 5). These findings indicate that NRIP inhibits the association between DDB2 and AR. Since NRIP binds either DDB1 or AR, in order to distinguish whether NRIP's protection of AR from DDB2 degradation is through NRIP associating with DDB1-CUL4A complex or binding to AR; we chose to use NRIP-DM mutant that lacks DDB1 binding but still interacts with AR for competition assay. LNCaP cells were cotransfected with an expression vector for Myc-tagged DDB2 alone or with an expression vector for FLAG-tagged NRIP-DM. Co-immunoprecipitation indicated that overexpression of NRIP-DM still interfered with the association between DDB2 and the AR (Figure 5E, lane 3). Taken together, the evidence suggests that the effect of NRIP on AR expression does not depend on its association with the DDB1-CUL4 complex and that displacement of DDB2 by NRIP will result in interaction with the AR protein and, thereby, in AR protein stabilization (Figure 5F).

\section{Co-expression of NRIP and the AR are found frequently in low-DDB2 expressing cribriform prostate cancer}

In the prostate cancer cell line LNCaP, NRIP displaced DDB2 to prevent DDB2 degrading the AR in the CUL4-DDB2-E3 ligase complex (Figure 5). We sought to determine whether, in human prostate cancer tissues, the expression patterns of these three proteins could match the specific mode of NRIP-DDB2-AR interaction revealed by our in vitro study. Most prostate cancer tissues are acinar adenocarcinomas [36] and can be further categorized into several subtypes, based on their cytoarchitectural features [37-39]. Among them, cancer with the cribriform pattern, or the intraductal carcinoma of the prostate [37-39], is a special subtype of prostate cancers associated with poor prognosis. It is named after the feature of solid lesions comprising tumor cells that span or fill glandular lumens but preserve, at least focally, a basal cell lining. Initially we noticed that $\sim$ one fifths of our prostate cancer samples were cribriform tumors; we then analyzed the expression patterns of NRIP, AR, and DDB2 in the context of the prostate cancers with or without the cribriform pattern (Figure 6A and 6B). As shown in Figure 6B, the highest percentage of tumors $(34.7 \%)$ with cribriform pattern was found in the group that were low for DDB2, high for NRIP, and high for AR. This is consistent with our hypothesis model in vitro (Figure 5F). Furthermore, high expression levels of both NRIP and AR, along with low expression levels of DDB2, compared with all the other seven possible expression patterns of these three proteins (Figure 6C), were found more frequently (odds ratio: $3.52,95 \%$ confidence interval: 1.70-7.29, $P<$ $0.0005)$ in the same lesions of prostate cancer with the cribriform pattern than in all other types prostate cancer, which were categorized as non-cribriform tumors. On the other hand, because the majority $(73 \% ; 170 / 232)$ of our prostate cancer tissues expressed low levels of DDB2 (Supplementary Table 2), when only those low-level DDB2 tumors were considered in comparison, it became more obvious that high expression levels of both NRIP and AR were more frequently detected in the cribriform tumors (odds ratio: 4.83, 95\% confidence interval: 2.09 $11.15, \mathrm{P}<0.005)$, while other combinations of expression were found more frequently in non-cribriform tumors (Supplementary Table 2). In addition, we found that high expression levels of NRIP, AR or both were detected more frequently in the cribriform tumors than non-cribriform tumors (Supplementary Table 3). Collectively, the specific expression pattern of NRIP, AR and DDB2 in the cribriform type of human prostate cancer is consistent with our hypothesis that NRIP protects against AR degradation 

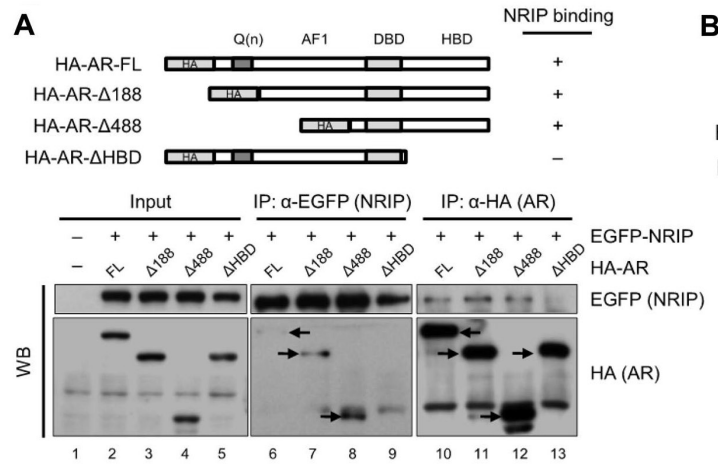

C

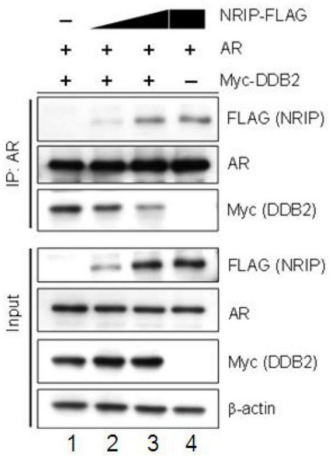

E

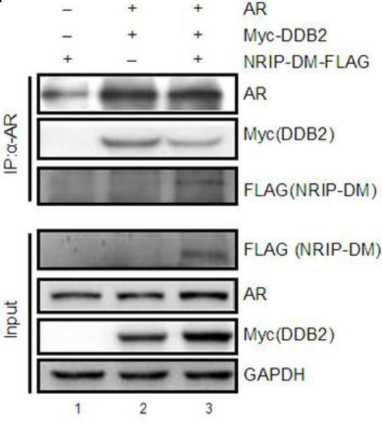

B

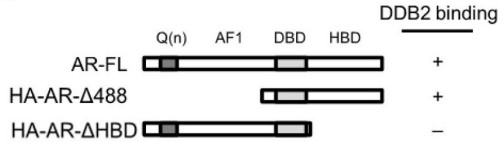

D

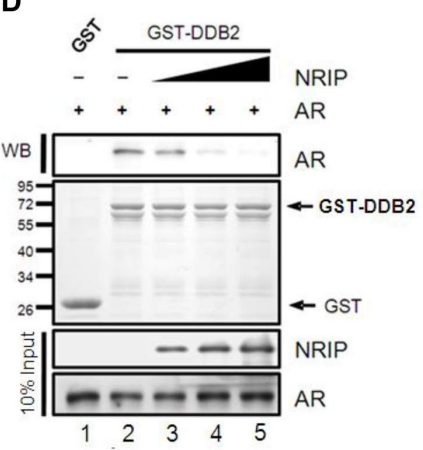

$\mathbf{F}$

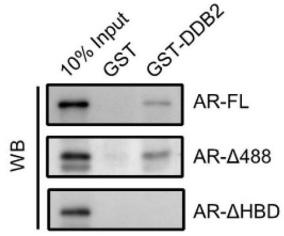

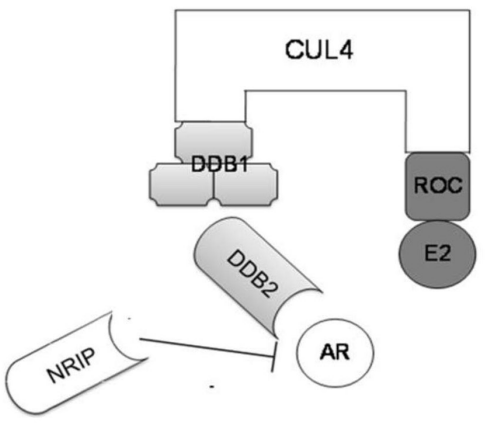

Figure 5: NRIP competes with DDB2 for AR but not DDB1 binding. A. NRIP binds the AR at HBD. Upper panel: a schematic figure of HA-AR-FL and various mutants of HA-AR, including HA-AR $\triangle 188$, HA-AR $\triangle 488$ and HA-AR $\triangle H B D$. This figure indicates that the C-terminal HBD of the AR was required for NRIP binding. Lower panel: 293T cells were cotransfected with EGFP-NRIP and various mutant forms of the AR, as shown in the upper panel. After $24 \mathrm{~h}$, proteins were extracted by RIPA buffer and subjected to immunoprecipitation with anti-EGFP or anti-HA antibodies. The expression of EGFP-NRIP, HA-AR-FL and HA-AR mutants was detected by western blotting with antiEGFP and anti-HA antibodies, respectively. Arrows: the positive signals detected by anti-HA antibody. Lanes 1 to $5: 10 \%$ of the input used for immunoprecipitation to assess comparable protein levels. Lanes 6 to 9: the immunoprecipitation performed with anti-EGFP. Lanes 10 to 13: the immunoprecipitation performed with anti-HA. B. The C-terminal HBD of the AR is required for DDB2 binding. Upper panel: a schema of HA-AR-FL and various mutants of HA-AR, including HA-AR 488 and HA-AR $\triangle H B D$. This figure indicates that the C-terminal HBD of the AR was required for DDB2 binding. Lower panel: the HA-AR-FL, HA-AR $\triangle 488$ and HA-AR $\triangle$ HBD were incubated with GST-DDB2 and followed by GST-pull down assay. The binding of HA-AR-FL, HA-AR $\triangle 488$ and HA-AR $\triangle$ with DDB2 were then analyzed by western blotting. C. NRIP competes with DDB2 for AR interaction. Cotransfection of 293T cells with expression vectors, including AR and Myc-DDB2, along with increasing amounts of FLAG-NRIP, was performed as indicated. The empty expression vector was used as a filler to maintain a constant amount of total plasmid DNA in all transfections. The cell lysates were subjected to immunoprecipitation $48 \mathrm{~h}$ after transfection using antiAR antibodies and then to western blotting using anti-FLAG and anti-Myc antibodies to detect NRIP and DDB2, respectively. D. In vitro competition of the binding of DDB2 and the AR in the presence of NRIP. GST-DDB2 produced from bacteria was incubated with AR protein and various amounts of NRIP, followed by in vitro GST-pull down assay. After adding NRIP, the interaction of AR and DDB2 decreased. E. NRIP-DM mutant competes with DDB2 for binding AR in cells. To determine whether AR or DDB1 binding is required for NRIP displacement of DDB2, 293T cells were transiently transfected with two or all three of the following: FLAG-tagged NRIP-DM, Myc-DDB2, and HA-AR. The total amount of plasmid DNA was kept constant by adding empty plasmid DNA. The cell extracts were harvested after $48 \mathrm{~h}$ and subjected to immunoprecipitation with AR antibody. The immunoprecipitates were analyzed by western blotting for the detection of the AR, Myc-DDB2, and FLAG-NRIP-DM with the antibodies indicated. The inputs represent $5 \%$ of the cell extracts used in immunoprecipitation. F. A schematic model of AR degradation via DDB2-DDB1-CUL4A-ROC1. NRIP also interacts with CUL4A-DDB1 but functions to stabilize AR protein. The schema shows that NRIP competed with DDB2 for binding to DDB1 or AR. 
by DDB2 in the CUL4-DDB1 E3 ligase complex, in at least a subset of prostate cancers.

\section{DISCUSSION}

In this study, we found that either NRIP (Figure 1) or the AR (Figure 2) was highly expressed in human prostate cancer tissues. Consistently, there was a positive correlation between the expression of NRIP and the AR (Table 1). The roles of the AR in prostate cancer are complex; the AR can be either tumor-inductive or tumorsuppressive, depending on which histological regions cancer cells are derived from [40, 41]. For example, when overexpressed in cancers derived from basal epithelial cells, the AR functions as a tumor suppressor to inhibit the proliferation of basal cells and drive them

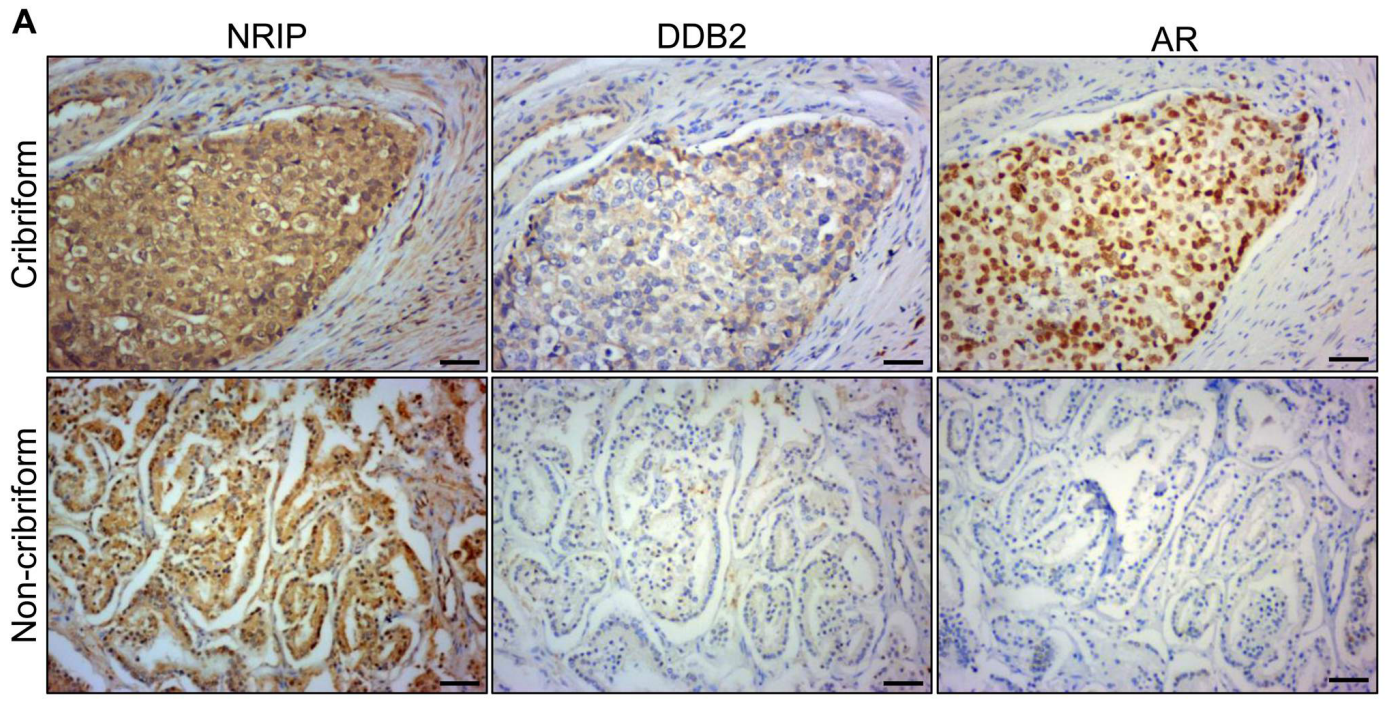

B

\begin{tabular}{cccccccccc}
\hline No. & & 1 & 2 & 3 & 4 & 5 & 6 & 7 & 8 \\
\hline & DDB2 & Low & Low & Low & Low & High & High & High & High \\
\hline NRIP & High & Low & High & Low & High & Low & High & Low \\
\hline AR & High & High & Low & Low & High & High & Low & Low \\
\hline Cribriform \% & $34.7(17 / 49)$ & $0(0 / 12)$ & $15.4(12 / 78)$ & $0(0 / 31)$ & $17.9(7 / 39)$ & $0(0 / 1)$ & $19(4 / 21)$ & $100^{*}(1 / 1)$ \\
\hline
\end{tabular}

* one case only

C

\begin{tabular}{cccc}
\hline & $\begin{array}{c}\text { NRIP high } \\
\text { AR high } \\
\text { DDB2 Low } \\
\text { expression }\end{array}$ & $\begin{array}{c}\text { all other } \\
\text { combinations }\end{array}$ & Total \\
\hline Cribriform & 17 & 24 & 41 \\
\hline Non-cribriform & 32 & 159 & 191 \\
\hline Total & 49 & 183 & 232 \\
\hline Odds ratio: 3.52; 95\% Conf. Interval: 1.70 7.29; Chi square P value=0.0004
\end{tabular}

Figure 6: The expression pattern with high levels of NRIP and AR, together with a low level of DDB2, is more frequently found in human cribriform prostate cancer tissues. A. Representative immunohistochemistry staining images of NRIP, DDB2 and AR expression in non-cribriform and cribriform prostate cancer tissues. Upper panel: cribriform tumors. Lower panel: non-cribriform tumors. Brown: the positive stain of NRIP, DDB2 or AR. Blue: hematoxylin counterstain. Scale bars: $50 \mu \mathrm{m}$. B.. Distribution percentage of eight different combinations of expression pattern of NRIP, DDB2 and AR in non-cribriform and cribriform prostate cancer tissues. Percentage $=$ cribriform $/$ cribriform + non-cribriform $\times 100 \%$. C. A chi square test to compare the distribution of NRIP-high/AR-high/ DDB2-low expression pattern and all other combinations of expression pattern for NRIP, DDB2 and AR in non-cribriform and cribriform prostate cancer tissues. 
into differentiation, resulting in the inhibition of prostate cancer metastasis $[40,42]$. In contrast, the AR is a survival factor that promotes the proliferation of luminal cellsthat constitute more than $99 \%$ of prostate tumor epithelial cells $[40,43]$. Here, we report that AR expression increased in prostate cancer tissues and support the proposed model of the AR as an oncogene in cancer. Like the AR, NRIP is an androgen-regulated gene [2] and our current data support the view that it acts as an oncoprotein in prostate cancer. In this regard, there are quite a few precedents, such as prostatic secretory protein-94, PSA, and TMPRSS2, all of which are products of androgen-regulated genes and enhance the progression of prostate cancer [44]. In this study, we reveal NRIP to be a new member of this list of proteins implicated in the pathogenesis of prostate cancer.

Several studies have shown that DDB2 acts a role as a tumor suppressor in a wide range of cancers, including UV-induced skin cancers [13], ovarian cancer [17], breast cancer [19, 20] and colon cancer [18]. Consistently, our data support that DDB2 functions as a tumor suppressor in prostate cancers. More importantly, our previous in vitro study indicated that DDB2 enhances the ubiquitination and proteasomal degradation of the AR, mediated by the DDB2-DDB1-Cul4 complex [23]. However, when the correlation between the expression levels of DDB2 and the AR in human prostate cancer tissues was analyzed, a positive correlation of the expression of these two proteins was revealed (Supplementary Table 1A), an observation that may not match our proposed model of DDB2-mediated AR degradation in the LNCaP cell line. However, this phenomenon may be explained by the fact that DDB2, in addition to its role as a tumor suppressor in many cancers, as outlined above, DDB2 also acts as damaged DNA binding protein to detect cancer chromosome instability [45]. There is evidence that DNA repair-related genes are activated by the AR in LNCaP cells treated with androgen [46]. Accordingly, DDB2 expression may be induced in prostate cancer tissues with high levels of AR expression. Interestingly, in another hormone-related cancer, breast cancer, overexpression of DDB2 has been reported in tumors of the non-invasive type [20] and another study demonstrated that the expression of DDB2 is higher in ER-positive than ER-negative breast tumors [47]. These studies also revealed that high levels of DDB2 expression in cancer tissues might be involved in DNA repair. Therefore, the correlation of AR and DBB2 expression in prostate cancers seems logical, because high levels of AR expression in cancer cells may activate the DNA repair mechanism that up-regulates DDB2 expression.

DCAFs are DDB1- and CUL4-binding proteins that are part of a large family of WD40 repeat-containing proteins [33, 48-50]. Almost all of these DCAFs have two conserved DxR motifs within the WD40 domain that are essential for DDB1 binding. DDB2 is the bestcharacterized DCAF and is needed for DDB1-CUL4Amediated ubiquitination of certain substrates [8, 48]. Like
DDB2, NRIP contains a double DxR box (Figure 4C), which is predicted to be solvent-exposed and located at the bottom of the WD40 propeller fold (an important determinant for the binding to DDB1). In the present study, we demonstrated that NRIP, like DDB2, interacts with the DDB1-CUL4A complex (Figure 4). Furthermore, we found that NRIP competes with DDB2 for binding sites on the DDB1-CUL4A complex, because these two DCAFs can both interact with DDB1 and AR to form the DDB1-CUL4A complex and share the same hormonebinding domain (HBD) of AR for interaction (Figure 5A and $5 \mathrm{~B}$ ). It is possible that NRIP blocks interaction with either DDB1-DDB2 or DDB2-AR. Our data showed that both NRIP and NRIP-DM (with an AR binding site but no DDB1 binding site) interfered with the interaction of DDB2 and AR, indicating that NRIP actually competes with DDB2 for AR binding but has no effect on DDB1 (Figure 5E). In a previous study [23], we showed that, in the absence of DDB1, CUL4A in LNCaP cells increases the AR protein level but introduction of DDB1 reduces AR protein, implying that once NRIP complexes with DDB1-CUL4A, the concentration of DDB1 and CUL4A needed to assemble into the AR-degrading DDB2-DDB1CUL4A complex is too low in certain compartments. These data show that NRIP prevents AR degradation by interfering with DDB2 assembly into DDB2-DDB1CUL4A complexes. On the other hand, NRIP-DM mutant can interact with AR but not DDB1 and can stabilize AR as well as wild-type NRIP. Collectively, there are at least two mechanisms for NRIP to stabilize AR; one is through directly association with AR; the other is through forming a complex with DDB1-CUL4A to decrease its binding to DDB2. Additionally, as for the distribution of these proteins in normal prostate tissues, NRIP was expressed both in basal cells and luminal cells; AR mostly in luminal cells and few in basal cells; DDB2 mostly in basal cells and rarely in luminal cell. It will be interesting for future to decide how and where for NRIP and DDB2 to compete either CUL4A-DDB1 complex or AR in normal condition.

There are two reasons why we separated tumors into cribriform and non-cribriform subtypes in our analysis. First, in our initial assessment of pathology slides of prostate tumors that were immuno-stained for DDB2, NRIP, and AR, we already found that some cribriform tumors had distinct expression patterns for these 3 proteins and thus we decided to clarify it using complete statistical analysis. Second, prostate cancers with the cribriform pattern have been well recognized as high-Gleason score tumors [37-39, 51]. The presence of the cribriform pattern is a strong predictor of metastasis, as well as diseasespecific death, in patients treated with radical prostatectomy [52]. A study of 241 radical prostatectomy specimens with the highest Gleason grade of 4 found that patients with tumors with the cribriform pattern tend to have biochemical recurrence and metastasis after radical prostatectomy [53]. It also has been reported that cribriform cancer carries a 
distinctly adverse clinical outcome [53, 54]. Our results indicated that a specific pattern of high expression of NRIP and AR and simultaneous low expression of DDB2 was detected more frequently in cribriform tumors than in non-cribriform tumors (Figure 6). Such a unique expression combination is reasonable from the perspective of our hypothetical model of NRIP's role in protecting AR degradation from the DDB2-DDB1-CUL4A. In addition, cribriform prostate cancer possesses other unique molecular and genetic features; for example, p63, high molecular weight cytokeratin, and TMPRSS2-ERG gene fusion are reportedly significantly more common in cribriform tumors than non-cribriform tumors $[55,56]$. The cross talks between these abnormally expressed molecules and the NRIP/DDB2-AR system may be related to the development of the specific morphological and clinical features seen in cribriform tumors and deserves further study.

In summary, we propose that NRIP and DDB2, through competitive binding to the AR, antagonize each other's function in maintaining $\mathrm{AR}$ homeostasis and disruption of the balance between these two proteins may contribute to the pathogenesis of a specific type of aggressive prostate cancer.

\section{MATERIALS AND METHODS}

\section{Human prostate cancer}

The human prostate biopsies were obtained from the National Taiwan University Hospital (NTUH) Tissue Bank; prostate cancer tissue arrays (serial numbers: PR953, PR955, PR483b, PR753 and PR8010) were purchased from US Biomax, Inc (Rockville, MD, USA). Studies involving human prostate tissues were approved by the Institutional Review Boards at National Taiwan University (NTU). The Gleason scores of each sample were provided by the original sources, NTUH Tissue Bank and US Biomax Inc.

\section{Immunohistochemistry}

For immunohistochemistry staining, the paraffinembedded sections were probed with anti-NRIP (GeneTex, GTX10595; 1:100), DDB2 (Santa Cruz, sc-25368; 1:50), and AR (DAKO, M356201; 1:100) antibodies. All these antibodies have been published previously in the literature for immunohistochemistry purpose $[57,58]$. The specificity of each antibody was confirmed in human prostate cancer tissue by immunohistochemistry without each primary antibody.

\section{Immunohistochemistry scores of protein expressions}

Immunohistochemistry scores of DDB2, NRIP and AR expression were obtained by multiplying the intensity scores and the extent scores, which were given double-blindly by two different researchers with pathology training. The intensity score was from zero to three, with 0 representing no staining (negative), 1 representing weak staining, 2 representing intermediate staining, while 3 representing strong staining [59]. The extent score was calculated by the percentage (scored as $0-100 \%$ ) of entire prostate gland areas on the slides of patient specimens from NTUH or of each dot on the tissue arrays from US Biomax Inc. The total score was obtained by multiplication of intensity by extent, from 0 to 300 . The tissues scoring higher than 150 were defined as having high expression for NRIP and AR staining. As for DDB2, the cut-off value of high expression was set at 125 [58]. A recent study comparing the results between the automated measures (such as ImageJ) and manual scoring concluded that both methods resulted in essentially identical scores when applied to patient biopsies [60].

\section{Reverse-transcriptase polymerase chain reaction (RT-PCR)}

Total RNAs were isolated with TRIzol reagent (Invitrogen) and treated with DNase (RQ1, Promega) to remove genomic DNA according to the manufacturers' instructions. One microgram of RNA was reversetranscribed into cDNA by SuperScript ${ }^{\mathrm{TM}}$ III First-Strand Synthesis System (Invitrogen) and subjected to PCR. The forward primer sequence of PSA was 5'-ATGTG GGTCCCGGTTGTCTTCCTCACC-3'. The reverse primer sequence of PSA was 5'-TCAGGGGTTGGCCA CGATGGTGTCCTT-3'. The forward primer sequence of GAPDH was 5'-ACCTTCAACACCCCAGCCATG-3'. The reverse primer sequence of GAPDH was 5'-CTG GAAGAGTGCCTCAGGGCA-3'.

\section{Plasmid construction}

The construction of FLAG-NRIP and His-NRIP were described previously [4]. The FLAG-NRIP-double mutant (DM, the DxR mutations in which the arginine [R] residues at aa 173 and aa 223 were changed to alanine [A] with the intact AR binding site but without functional DDB1 binding site) plasmid were mutated and generated from FLAG-NRIP in such a way that the aspartic acids at 173 and 223 in the regions bounded by amino acid residues 166 to 179 and 216 to 229 were replaced by alanine using PCR-based site-directed mutagenesis (Figure 4C). The construction of GSTDDB2 was described previously [23]. The construction of plasmids-pcDNA3.0-AR was described previously [2]. Plasmids expressing HA-DDB1, Myc-DDB2 were kindly provided by Dr. Yun Xiong (University of North Carolina, Chapel Hill, NC), the pSG5-AR or deletion mutants were from Dr. Andrew C.B. Cato (Forschungszentrum Karlsruhe, Institute of Genetics, Karlsruhe, Germany) [61]. 


\section{Cell culture and transfection}

293T cells were transfected with the plasmids indicated in growth medium using calcium phosphate $[2,4,23]$. LNCaP cells were transfected with FuGENE 6 (Roche Applied Science) or SuperFect (Qiagen) transfection reagents according to the manufacturers' instructions [1].

\section{Coimmunoprecipitation and western blotting}

Proteins were extracted from transfected 293T and LNCap cells and subjected to coimmunoprecipitation assay $[2,23]$ and western blot analysis for primary antibody incubation. Antibodies included anti-HA (1:2000, Abcam, MA, USA), anti-Flag (1:2000, Sigma, MO, USA), anti-AR (1:1000, Santa Cruz, TX, USA), antiNRIP (1:1000, Abnova, Taipei, Taiwan) and anti-GAPDH (1:5000, Abfronteier, Seoul, Korea).

\section{Statistical analysis}

Chi-square $\left(\chi^{2}\right)$ test or Student's t-test were used to evaluate the differences between two different parameters (e.g. protein expression scores and Gleason scores). A P-value of less than 0.05 was considered statistically significant.

\section{ACKNOWLEDGMENTS}

This work was supported by the Ministry of Science and Technology (MOST 104-2320-B-002-053MY3; MOST 105-2320-B-002-039-MY3), the National Health Research Institute (NHRI-105-1053ISI), and National Taiwan University (10R891903). Wethank Dr. Ming-Shyue Lee and Dr. Hung-Chih Yang for critical discussions; Dr. Chi-Ling Chen for statistical analysis and Dr. Tim J. Harrison for language editing. Thanks to Dr. Yun Xiong (University of North Carolina, Chapel Hill, $\mathrm{NC}$ ) for providing plasmids (HA-DDB1 and Myc-DDB2); and Dr. Andrew C.B. Cato (Forschungszentrum Karlsruhe, Institute of Genetics, Karlsruhe, Germany)for pSG5-AR or deletion mutants.

\section{CONFLICTS OF INTEREST}

The authors declare no conflicts of interest.

\section{REFERENCES}

1. Tsai TC, Lee YL, Hsiao WC, Tsao YP, Chen SL. NRIP, a novel nuclear receptor interaction protein, enhances the transcriptional activity of nuclear receptors. J Biol Chem. 2005; 280:20000-20009.

2. Chiang TA, Chen PH, Wu PF, Wang TN, Chang PY, Ko AM, Huang MS, Ko YC. Important prognostic factors for the long-term survival of lung cancer subjects in Taiwan. BMC Cancer. 2008; 8:324.

3. Jin J, Arias EE, Chen J, Harper JW, Walter JC. A family of diverse Cul4-Ddb1-interacting proteins includes Cdt2, which is required for $\mathrm{S}$ phase destruction of the replication factor Cdt1. Mol Cell. 2006; 23:709-721.

4. Chang SW, Tsao YP, Lin CY, Chen SL. NRIP, a novel calmodulin binding protein, activates calcineurin to dephosphorylate human papillomavirus E2 protein. J Virol. 2011; 85:6750-6763.

5. Nakano K, Miki Y, Hata S, Ebata A, Takagi K, McNamara KM, Sakurai M, Masuda M, Hirakawa H, Ishida T, Suzuki T, Ohuchi N, Sasano H. Identification of androgenresponsive microRNAs and androgen-related genes in breast cancer. Anticancer Res. 2013; 33:4811-4819.

6. Han CP, Lee MY, Tzeng SL, Yao CC, Wang PH, Cheng YW, Chen SL, Wu TS, Tyan YS, Kok LF. Nuclear Receptor Interaction Protein (NRIP) expression assay using human tissue microarray and immunohistochemistry technology confirming nuclear localization. J Exp Clin Cancer Res. 2008; 27:25.

7. Bosch DG, Boonstra FN, de Leeuw N, Pfundt R, Nillesen WM, de Ligt J, Gilissen C, Jhangiani S, Lupski JR, Cremers FP, de Vries BB. Novel genetic causes for cerebral visual impairment. Eur J Hum Genet. 2016; 24:660-665.

8. He YJ, McCall CM, Hu J, Zeng Y, Xiong Y. DDB1 functions as a linker to recruit receptor WD40 proteins to CUL4-ROC1 ubiquitin ligases. Genes Dev. 2006; 20:2949-2954.

9. Scrima A, Konickova R, Czyzewski BK, Kawasaki Y, Jeffrey PD, Groisman R, Nakatani Y, Iwai S, Pavletich NP, Thoma NH. Structural basis of UV DNA-damage recognition by the DDB1-DDB2 complex. Cell. 2008; 135:1213-1223.

10. Itoh $\mathrm{T}, \mathrm{O}$ 'Shea $\mathrm{C}$, Linn $\mathrm{S}$. Impaired regulation of tumor suppressor p53 caused by mutations in the xeroderma pigmentosum DDB2 gene: mutual regulatory interactions between p48(DDB2) and p53. Mol Cell Biol. 2003; 23:7540-7553.

11. Stoyanova T, Roy N, Kopanja D, Bagchi S, Raychaudhuri P. DDB2 decides cell fate following DNA damage. Proc Natl Acad Sci U S A. 2009; 106:10690-10695.

12. Matsuda N, Azuma K, Saijo M, Iemura S, Hioki Y, Natsume T, Chiba T, Tanaka K, Tanaka K. DDB2, the xeroderma pigmentosum group $\mathrm{E}$ gene product, is directly ubiquitylated by Cullin 4A-based ubiquitin ligase complex. DNA Repair (Amst). 2005; 4:537-545.

13. Stoyanova T, Roy N, Bhattacharjee S, Kopanja D, Valli T, Bagchi S, Raychaudhuri P. p21 cooperates with DDB2 protein in suppression of ultraviolet ray-induced skin malignancies. J Biol Chem. 2012; 287:3019-3028.

14. Barckhausen C, Roos WP, Naumann SC, Kaina B. Malignant melanoma cells acquire resistance to DNA interstrand cross-linking chemotherapeutics by 
p53-triggered upregulation of DDB2/XPC-mediated DNA repair. Oncogene. 2014; 33:1964-1974.

15. Hu Z, Shao M, Yuan J, Xu L, Wang F, Wang Y, Yuan W, Qian J, Ma H, Wang Y, Liu H, Chen W, Yang L, et al. Polymorphisms in DNA damage binding protein 2 (DDB2) and susceptibility of primary lung cancer in the Chinese: a case-control study. Carcinogenesis. 2006; 27:1475-1480.

16. Barakat BM, Wang QE, Han C, Milum K, Yin DT, Zhao Q, Wani G, Arafa el SA, El-Mahdy MA, Wani AA. Overexpression of DDB2 enhances the sensitivity of human ovarian cancer cells to cisplatin by augmenting cellular apoptosis. Int J Cancer. 2010; 127:977-988.

17. Han C, Zhao R, Liu X, Srivastava A, Gong L, Mao H, Qu M, Zhao W, Yu J, Wang QE. DDB2 suppresses tumorigenicity by limiting the cancer stem cell population in ovarian cancer. Mol Cancer Res. 2014; 12:784-794.

18. Roy N, Bommi PV, Bhat UG, Bhattacharjee S, Elangovan I, Li J, Patra KC, Kopanja D, Blunier A, Benya R, Bagchi S, Raychaudhuri P. DDB2 suppresses epithelial-tomesenchymal transition in colon cancer. Cancer Res. 2013; 73:3771-3782.

19. Minig V, Kattan Z, van Beeumen J, Brunner E, Becuwe P. Identification of DDB2 protein as a transcriptional regulator of constitutive SOD2 gene expression in human breast cancer cells. J Biol Chem. 2009; 284:14165-14176.

20. Ennen M, Klotz R, Touche N, Pinel S, Barbieux C, Besancenot V, Brunner E, Thiebaut D, Jung AC, Ledrappier S, Domenjoud L, Abecassis J, Plenat F, et al. DDB2: a novel regulator of NF-kappaB and breast tumor invasion. Cancer Res. 2013; 73:5040-5052.

21. Zhao R, Cui T, Han C, Zhang X, He J, Srivastava AK, Yu J, Wani AA, Wang QE. DDB2 modulates TGF-beta signal transduction in human ovarian cancer cells by downregulating NEDD4L. Nucleic Acids Res. 2015; 43:7838-7849.

22. Qiao S, Guo W, Liao L, Wang L, Wang Z, Zhang R, Xu D, Zhang Y, Pan Y, Wang Z, Chen Y. DDB2 is involved in ubiquitination and degradation of PAQR3 and regulates tumorigenesis of gastric cancer cells. Biochem J. 2015; 469:469-480.

23. Chang SW, Su CH, Chen HH, Huang CW, Tsao LP, Tsao YP, Chen SL. DDB2 is a novel AR interacting protein and mediates AR ubiquitination/degradation. Int J Biochem Cell Biol. 2012; 44:1952-1961.

24. Heinlein CA, Chang C. Androgen receptor in prostate cancer. Endocr Rev. 2004; 25:276-308.

25. Niu Y, Chang TM, Yeh S, Ma WL, Wang YZ, Chang C. Differential androgen receptor signals in different cells explain why androgen-deprivation therapy of prostate cancer fails. Oncogene. 2010; 29:3593-3604.

26. Lonergan PE, Tindall DJ. Androgen receptor signaling in prostate cancer development and progression. J Carcinog. $2011 ; 10: 20$.
27. Culig Z, Santer FR. Androgen receptor signaling in prostate cancer. Cancer Metastasis Rev. 2014; 33:413-427.

28. Vatten LJ, Ursin G, Ross RK, Stanczyk FZ, Lobo RA, Harvei S, Jellum E. Androgens in serum and the risk of prostate cancer: a nested case-control study from the Janus serum bank in Norway. Cancer Epidemiol Biomarkers Prev. 1997; 6:967-969.

29. Qiu YQ, Leuschner I, Braun PM. Androgen receptor expression in clinically localized prostate cancer: immunohistochemistry study and literature review. Asian J Androl. 2008; 10:855-863.

30. Itoh T, Iwashita S, Cohen MB, Meyerholz DK, Linn S. Ddb2 is a haploinsufficient tumor suppressor and controls spontaneous germ cell apoptosis. Hum Mol Genet. 2007; 16:1578-1586.

31. Yoon T, Chakrabortty A, Franks R, Valli T, Kiyokawa H, Raychaudhuri P. Tumor-prone phenotype of the DDB2deficient mice. Oncogene. 2005; 24:469-478.

32. Shiyanov P, Hayes SA, Donepudi M, Nichols AF, Linn S, Slagle BL, Raychaudhuri P. The naturally occurring mutants of DDB are impaired in stimulating nuclear import of the p125 subunit and E2F1-activated transcription. Mol Cell Biol. 1999; 19:4935-4943.

33. Lee J, Zhou P. DCAFs, the missing link of the CUL4-DDB1 ubiquitin ligase. Mol Cell. 2007; 26:775-780.

34. Fukumoto Y, Dohmae N, Hanaoka F. Schizosaccharomyces pombe Ddb1 recruits substrate-specific adaptor proteins through a novel protein motif, the DDB-box. Mol Cell Biol. 2008; 28:6746-6756.

35. Centenera MM, Harris JM, Tilley WD, Butler LM. The contribution of different androgen receptor domains to receptor dimerization and signaling. Mol Endocrinol. 2008; 22:2373-2382.

36. Humphrey PA. Histological variants of prostatic carcinoma and their significance. Histopathology. 2012; 60:59-74.

37. Dema A, Borda A, Lazar E, Lazureanu C, Taban S, Anderco D, Cornianu M, Muresan A, Herman D, Loghin A, Cornea R, Faur A. Prostate lesions with cribriform / pseudocribriform pattern. Rom J Morphol Embryol. 2010; 51:413-425.

38. Latour M, Amin MB, Billis A, Egevad L, Grignon DJ, Humphrey PA, Reuter VE, Sakr WA, Srigley JR, Wheeler TM, Yang XJ, Epstein JI. Grading of invasive cribriform carcinoma on prostate needle biopsy: an interobserver study among experts in genitourinary pathology. Am J Surg Pathol. 2008; 32:1532-1539.

39. Robinson B, Magi-Galluzzi C, Zhou M. Intraductal carcinoma of the prostate. Arch Pathol Lab Med. 2012; 136:418-425.

40. Niu Y, Altuwaijri S, Yeh S, Lai KP, Yu S, Chuang KH, Huang SP, Lardy H, Chang C. Targeting the stromal androgen receptor in primary prostate tumors at earlier stages. Proc Natl Acad Sci U S A. 2008; 105:12188-12193. 
41. Yu SQ, Lai KP, Xia SJ, Chang HC, Chang C, Yeh S. The diverse and contrasting effects of using human prostate cancer cell lines to study androgen receptor roles in prostate cancer. Asian J Androl. 2009; 11:39-48.

42. Tian J, Lee SO, Liang L, Luo J, Huang CK, Li L, Niu Y, Chang C. Targeting the unique methylation pattern of androgen receptor (AR) promoter in prostate stem/ progenitor cells with 5-aza-2'-deoxycytidine (5-AZA) leads to suppressed prostate tumorigenesis. J Biol Chem. 2012; 287:39954-39966.

43. Packer JR, Maitland NJ. The molecular and cellular origin of human prostate cancer. Biochim Biophys Acta. 2016; 1863:1238-1260.

44. Reeves JR, Dulude H, Panchal C, Daigneault L, Ramnani DM. Prognostic value of prostate secretory protein of 94 amino acids and its binding protein after radical prostatectomy. Clin Cancer Res. 2006; 12:6018-6022.

45. Puumalainen MR, Lessel D, Ruthemann P, Kaczmarek N, Bachmann K, Ramadan K, Naegeli H. Chromatin retention of DNA damage sensors DDB2 and XPC through loss of p97 segregase causes genotoxicity. Nat Commun. 2014; 5:3695.

46. Polkinghorn WR, Parker JS, Lee MX, Kass EM, Spratt DE, Iaquinta PJ, Arora VK, Yen WF, Cai L, Zheng D, Carver BS, Chen Y, Watson PA, et al. Androgen receptor signaling regulates DNA repair in prostate cancers. Cancer Discov. 2013; 3:1245-1253.

47. Kattan Z, Marchal S, Brunner E, Ramacci C, Leroux A, Merlin JL, Domenjoud L, Dauca M, Becuwe P. Damaged DNA binding protein 2 plays a role in breast cancer cell growth. PLoS One. 2008; 3:e2002.

48. Angers S, Li T, Yi X, MacCoss MJ, Moon RT, Zheng N. Molecular architecture and assembly of the DDB1-CUL4A ubiquitin ligase machinery. Nature. 2006; 443:590-593.

49. Higa LA, Wu M, Ye T, Kobayashi R, Sun H, Zhang H. CUL4-DDB1 ubiquitin ligase interacts with multiple WD40-repeat proteins and regulates histone methylation. Nat Cell Biol. 2006; 8:1277-1283.

50. Hu J, McCall CM, Ohta T, Xiong Y. Targeted ubiquitination of CDT1 by the DDB1-CUL4A-ROC1 ligase in response to DNA damage. Nat Cell Biol. 2004; 6:1003-1009.

51. Epstein JI. Prostatic ductal adenocarcinoma: a mini review. Med Princ Pract. 2010; 19:82-85.

52. Kweldam CF, Wildhagen MF, Steyerberg EW, Bangma $\mathrm{CH}$, van der Kwast TH, van Leenders GJ. Cribriform growth is highly predictive for postoperative metastasis and diseasespecific death in Gleason score 7 prostate cancer. Mod Pathol. 2015; 28:457-464.
53. Dong F, Yang P, Wang C, Wu S, Xiao Y, McDougal WS, Young RH, Wu CL. Architectural heterogeneity and cribriform pattern predict adverse clinical outcome for Gleason grade 4 prostatic adenocarcinoma. Am J Surg Pathol. 2013; 37:1855-1861.

54. Iczkowski KA, Torkko KC, Kotnis GR, Wilson RS, Huang W, Wheeler TM, Abeyta AM, La Rosa FG, Cook S, Werahera PN, Lucia MS. Digital quantification of five high-grade prostate cancer patterns, including the cribriform pattern, and their association with adverse outcome. Am J Clin Pathol. 2011; 136:98-107.

55. Mosquera JM, Perner S, Demichelis F, Kim R, Hofer MD, Mertz KD, Paris PL, Simko J, Collins C, Bismar TA, Chinnaiyan AM, Rubin MA. Morphological features of TMPRSS2-ERG gene fusion prostate cancer. The Journal of pathology. 2007; 212:91-101.

56. Herawi M, Epstein JI. Immunohistochemical antibody cocktail staining (p63/HMWCK/AMACR) of ductal adenocarcinoma and Gleason pattern 4 cribriform and noncribriform acinar adenocarcinomas of the prostate. Am J Surg Pathol. 2007; 31:889-894.

57. Chen HH, Chen WP, Yan WL, Huang YC, Chang SW, Fu WM, Su MJ, Yu IS, Tsai TC, Yan YT, Tsao YP, Chen SL. NRIP is newly identified as a Z-disc protein, activating calmodulin signaling for skeletal muscle contraction and regeneration. J Cell Sci. 2015; 128:4196-4209.

58. Kuo PC, Huang CW, Lee CI, Chang HW, Hsieh SW, Chung YP, Lee MS, Huang CS, Tsao LP, Tsao YP, Chen SL. BCAS2 promotes prostate cancer cells proliferation by enhancing AR mRNA transcription and protein stability. Br J Cancer. 2015; 112:391-402.

59. Rizzardi AE, Johnson AT, Vogel RI, Pambuccian SE, Henriksen J, Skubitz AP, Metzger GJ, Schmechel SC. Quantitative comparison of immunohistochemical staining measured by digital image analysis versus pathologist visual scoring. Diagn Pathol. 2012; 7:42.

60. Choudhury KR, Yagle KJ, Swanson PE, Krohn KA, Rajendran JG. A robust automated measure of average antibody staining in immunohistochemistry images. The journal of histochemistry and cytochemistry. 2010; 58:95-107.

61. Shatkina L, Mink S, Rogatsch H, Klocker H, Langer G, Nestl A, Cato AC. The cochaperone Bag-1L enhances androgen receptor action via interaction with the NH2terminal region of the receptor. Mol Cell Biol. 2003; 23:7189-7197. 